\title{
Poly(vinyl pyrrolidone)-assisted hydrothermal synthesis and enhanced visible-light photocatalytic performance of oxygen-rich bismuth oxychlorides
}

\author{
Fei Chang ${ }^{\mathrm{a}, *}$, Jieru Luo ${ }^{\mathrm{a}}$, Xiaofang Wang ${ }^{\mathrm{a}}$, Yunchao Xie ${ }^{\mathrm{a}}$, Baoqing Deng ${ }^{\mathrm{a}}$, Xuefeng $\mathrm{Hu}^{\mathrm{b}, *}$ \\ ${ }^{a}$ School of Environment and Architecture, University of Shanghai for Science and Technology, Shanghai 200093, PR China

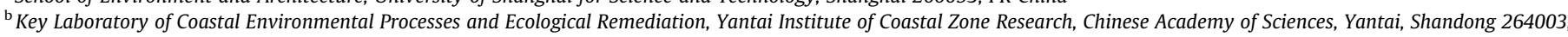
PR China

\section{G R A P H I C A L A B S T R A C T}

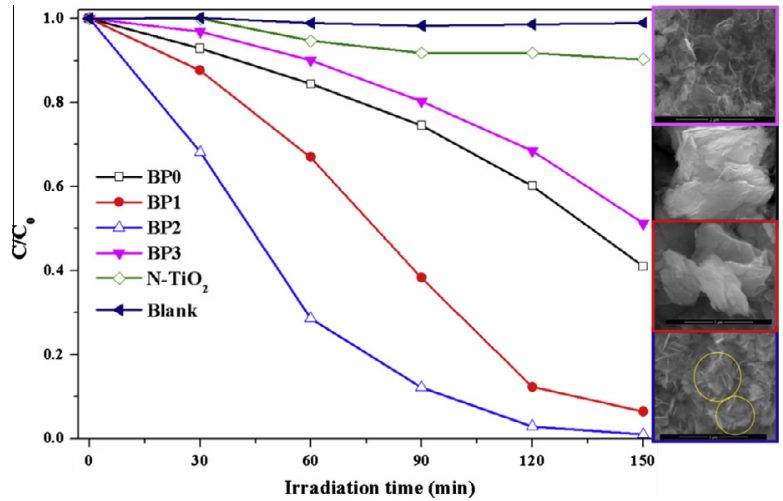

\section{A R T I C L E I N F O}

\section{Article history:}

Received 26 May 2015

Revised 10 August 2015

Accepted 11 August 2015

Available online 12 August 2015

\section{Keywords:}

$\mathrm{Bi}_{12} \mathrm{O}_{17} \mathrm{Cl}_{2}$

Poly(vinyl pyrrolidone)

Photocatalysis

Rhodamine $\mathrm{B}$

2,4-Dichlorophenol

Mechanism

\section{A B S T R A C T}

A series of novel oxygen-rich bismuth oxychloride $\left(\mathrm{Bi}_{12} \mathrm{O}_{17} \mathrm{Cl}_{2}\right)$ were synthesized through a facile poly (vinyl pyrrolidone) (PVP)-assisted hydrothermal route. These obtained $\mathrm{Bi}_{12} \mathrm{O}_{17} \mathrm{Cl}_{2}$ samples were characterized by various physicochemical techniques. It was found that a proper addition amount of PVP could promote the transformation of $\mathrm{Bi}_{12} \mathrm{O}_{17} \mathrm{Cl}_{2}$ morphology from irregular clusters to three-dimensional hierarchical flower-like microspheres that were nominated as sample BP2. As-synthesized samples were subjected to a photocatalytic degradation of dye Rhodamine B (RhB) or 2,4-dichlorophenol (2,4-DCP) under visible light. Among all candidates, the sample BP2 with a hierarchical flower-like morphology showed the best degradation efficiency for RhB and 2,4-DCP. The apparent rate constant of sample BP2 in terms of degradation of RhB was nearly 5.7 and 45 times that of unmodified $\mathrm{BP} 0$ and $\mathrm{N}-\mathrm{TiO}_{2}$. The enhanced photocatalytic performance could be ascribed to synergetic effects including unique hierarchical morphologies, large specific surface area, small particle size, good crystallinity, and suitable band structures. A possible mechanism of catalytic degradation was finally proposed basing upon the active species trapping experiments.

(c) 2015 Elsevier Inc. All rights reserved.

\footnotetext{
* Corresponding authors.

E-mail addresses: feichang@usst.edu.cn (F. Chang),xfhu@yic.ac.cn (X. Hu).
} 


\section{Introduction}

Heterogeneous photocatalysis has attracted considerable attention due to its potential applications in energy storage and environmental remediation [1-3]. Under irradiation, semiconductorbased photocatalysts are able to split water into $\mathrm{H}_{2}$ and $\mathrm{O}_{2}$ [2], destruct environmental pollutants [3], and reduce $\mathrm{CO}_{2}$ with $\mathrm{H}_{2} \mathrm{O}$ into hydrocarbon fuels [4]. Among generally used photocatalysts, titania $\left(\mathrm{TiO}_{2}\right)$ is the most widely researched one that, however, usually suffers from the low quantum efficiency and incapability of visible-light response. Therefore, it is indispensable to develop novel and low-cost visible-light-driven semiconductors with excellent catalytic activity and sufficient stability for practical utilizations [5].

It is demonstrated that bismuth oxyhalides ( $\mathrm{BiOX}, \mathrm{X}=\mathrm{F}, \mathrm{Cl}, \mathrm{Br}, \mathrm{I}$ ) feature lamellar structures with strong internal electric field, favoring the separation of photogenerated electron-hole pairs and hereby possessing superior catalytic performance [6-8]. Although numerous BiOX materials with different atomic ratios of $\mathrm{Bi} / \mathrm{O} / \mathrm{X}$ have been successfully prepared and developed as efficient photocatalysts [9-12], there are few literatures concerning systematical studies toward the synthesis and photocatalytic evaluation of $\mathrm{Bi}_{12} \mathrm{O}_{17} \mathrm{Cl}_{2}$, an oxygen-rich $\mathrm{BiOCl}$ candidate with favorable physicochemical properties. Chen et al. reported that $\mathrm{Bi}_{12} \mathrm{O}_{17} \mathrm{Cl}_{2}$ samples could be synthesized via tuning molar ratios of $\mathrm{BiCl}_{3} / \mathrm{NaOH}$ in an EtOH- $\mathrm{H}_{2} \mathrm{O}$ system [13]. Tien et al. demonstrated the successful production of $\mathrm{Bi}_{12} \mathrm{O}_{17} \mathrm{Cl}_{2}$ nanowires by chlorinating $\alpha-\mathrm{Bi}_{2} \mathrm{O}_{3}$ nanowires [14]. Xiao et al. first carried out the photocatalytic degradation of bisphenol $\mathrm{A}$ under visible light with $\mathrm{Bi}_{12} \mathrm{O}_{17} \mathrm{Cl}_{2}$ prepared through a one-pot hydrothermal route [15]. Xiao et al. conducted the selective oxidation of benzyl alcohol to benzaldehyde in presence of $\mathrm{Bi}_{12} \mathrm{O}_{17} \mathrm{Cl}_{2}$ nanobelts during visible-light photocatalytic process [16]. Very recently, He et al. reported a facile solvothermalcalcining process to prepare three-dimensional (3D) flower-like composites $\mathrm{Bi}_{12} \mathrm{O}_{17} \mathrm{Cl}_{2} / \beta-\mathrm{Bi}_{2} \mathrm{O}_{3}$ for the first time, which displayed superior catalytic behavior for degradation of 4-tert-butylphenol upon visible-light irradiation [17].As a result, to fulfill the requirement of real employments of photocatalytic processes toward toxic contaminants control and remediation in water body, it is urgent to design and develop lamellar $\mathrm{Bi}_{12} \mathrm{O}_{17} \mathrm{Cl}_{2}$ compounds with proper electronic structure, unique optical properties, and favorable morphologies, especially, 3D hierarchical superstructures, since these 3D ordered architectures possess structural merits of both a microstructure and a nanostructure, such as high crystallinity, high surface to volume ratio, and plenteous electronic transport paths, which are potentially beneficial to the separation of charge carriers and further improvement of photocatalytic performance [18].

In the present study, various oxygen-rich $\mathrm{Bi}_{12} \mathrm{O}_{17} \mathrm{Cl}_{2}$ sample were constructed by means of a PVP-assisted hydrothermal method for the first time. Structures and morphologies of obtained samples were characterized by a collection of techniques. The addition of PVP promoted the change of morphology in $\mathrm{Bi}_{12} \mathrm{O}_{17} \mathrm{Cl}_{2}$ samples. With the optimal amount of PVP, sample BP2 was generated as uniform 3D hierarchical microspheres. These ordered hierarchical architectures could not maintain with the insufficient and excess amount of PVP. The photocatalytic performance of these samples was measured through degradation of dye $\mathrm{RhB}$ and 2,4-DCP, a colorless and non-biodegradable organic pollutant in environment. Under visible light, sample BP2 displayed the best degradation outcome over both RhB and 2,4-DCP among all tested samples, mainly attributing to the favorable properties, such as the superior hierarchical morphologies, enlarged specific surface area, small average particle size, good crystallinity, and suitable band structures. Finally, a possible photocatalysis mechanism was proposed basing on experimental results.

\section{Experimental}

\subsection{Chemicals}

Bismuth nitrate pentahydrate $\left(\mathrm{Bi}\left(\mathrm{NO}_{3}\right)_{3} \cdot 5 \mathrm{H}_{2} \mathrm{O}, \mathrm{AR}\right)$, hydrochloric acid $(\mathrm{HCl}, 36-38 \%, \mathrm{AR})$, sodium hydroxide $(\mathrm{NaOH}, \mathrm{AR})$, poly (vinyl pyrrolidone) (PVP, K30), and other chemicals involved were purchased from Sinopharm Chemical Reagent Co., Ltd. (Shanghai, China) and used directly for experiments without any further purification. Deionized water was used throughout the experimental.

\subsection{Synthesis of $\mathrm{Bi}_{12} \mathrm{O}_{17} \mathrm{Cl}_{2}$ photocatalysts}

In a typical synthesis, $\mathrm{Bi}\left(\mathrm{NO}_{3}\right)_{3} \cdot 5 \mathrm{H}_{2} \mathrm{O}(3.84 \mathrm{mmol})$ was dissolved in a $\mathrm{HCl}$ aqueous solution ( $2 \mathrm{M}, 25 \mathrm{~mL}$ ), into which a aqueous solution $(20 \mathrm{~mL})$ containing different PVP amount was added dropwise upon stirring. Subsequently, $\mathrm{NaOH}$ solution (4 M, $20 \mathrm{~mL}$ ) was carefully added and the resultant suspension was continuously stirred for $0.5 \mathrm{~h}$ at room temperature. Then, the pale light suspension was transferred into a $100 \mathrm{~mL}$ stainless-steel Teflon-lined autoclave that placed in an oven and stayed at $160^{\circ} \mathrm{C}$ for $6 \mathrm{~h}$. After cooling to room temperature, the yellow precipitate was washed with deionized water and absolute ethanol for several times. After dried at $60{ }^{\circ} \mathrm{C}$ overnight, a powder was finally generated by annealing the precipitate at $500{ }^{\circ} \mathrm{C}$ for $4 \mathrm{~h}$. For convenience, the as-prepared $\mathrm{Bi}_{12} \mathrm{O}_{17} \mathrm{Cl}_{2}$ products obtained with different amounts of PVP $(0$, $0.1,0.2$, and $0.3 \mathrm{~g}$ ) were denoted as BP0, BP1, BP2, and BP3, respectively. $\mathrm{N}$-doped $\mathrm{TiO}_{2}\left(\mathrm{~N}-\mathrm{TiO}_{2}\right)$ was synthesized according to a previous report [19] and then subjected to photocatalytic tests for comparison.

\subsection{Characterization}

X-ray diffraction (XRD) patterns were recorded on a Bruker D8 Advance X-ray diffractometer using a $\mathrm{Cu} \mathrm{K} \alpha$ radiation source ( $\lambda=1.5406 \AA$ ). The general morphology of prepared samples was observed by means of scanning electron microscopy (SEM, Hitachi S-4800 and Hitachi S-4700). TEM, HRTEM patterns, and SAED images were recorded on a FEI Tecnai $G^{2}$ F20 transmission electron microscope operated at $200 \mathrm{kV}$. HRTEM was analyzed using the Digital Micrograph software (Gatan Inc.). X-ray photoelectron spectroscopy (XPS) measurements were performed by using a RBD upgraded PHI 5000C ESCA System (Perkin Elmer) with $\mathrm{Mg} \mathrm{K} \alpha(1253.6 \mathrm{eV})$ radiation. Binding energies were calibrated by using the containment carbon $(\mathrm{C} 1 \mathrm{~s}=284.6 \mathrm{~V})$. The valence-band $\mathrm{X}$-ray photoelectron spectroscopy (VB XPS) spectrum was obtained on a Thermo ESCALAB 250 spectrometer using a monochromated Al-Ka source $(1486.6 \mathrm{eV})$. The specific surface areas were measured using the BET method by Nitrogen adsorption-desorption isotherms at $77 \mathrm{~K}$ using a Micromeritics 3Flex apparatus. Before measurement, the samples were degassed at $383 \mathrm{~K}$ under vacuum for more than $12 \mathrm{~h}$. UV-vis diffuse reflectance spectra (UV-Vis DRS) were obtained on a Shimadzu UV-2600 spectrophotometer using $\mathrm{BaSO}_{4}$ as a reference. Photoluminescence (PL) spectra were measured with Edinburgh FLSP920 fluorescence spectrometer with an excitation wavelength of $324 \mathrm{~nm}$.

\subsection{Photocatalytic activity measurements}

Photocatalytic activity of the $\mathrm{Bi}_{12} \mathrm{O}_{17} \mathrm{Cl}_{2}$ samples were evaluated toward degradation of dye RhB and 2,4-DCP under visible light irradiation in a LIMX-VII apparatus by Bylabo Precision Instrument Co. Ltd. (Xi'an, China). Visible light irradiation was supplied by a $400 \mathrm{~W}$ halogen lamp, equipping with a $2 \mathrm{M}$ sodium 
nitrite solution to remove UV light with wavelength below $400 \mathrm{~nm}$ [20]. $\mathrm{Bi}_{12} \mathrm{O}_{17} \mathrm{Cl}_{2}$ sample ( $40 \mathrm{mg}$ ) was dispersed in an aqueous solution of RhB $\left(10 \mathrm{mg} \mathrm{L}^{-1}, 40 \mathrm{~mL}\right)$ or 2,4 -DCP $\left(5 \mathrm{mg} \mathrm{L}^{-1}, 40 \mathrm{~mL}\right)$ and the suspension was magnetically stirred for $1 \mathrm{~h}$ in dark to ensure an adsorption-desorption equilibrium before exposing to irradiation. At fixed time intervals, $4 \mathrm{~mL}$ aliquot was sampled and centrifuged to remove the suspended catalyst particles. The concentration of RhB was analyzed by a UV-Vis spectrophotometer (Sinopharm Chemical Reagent T6) at $554 \mathrm{~nm}$, and the residual 2, 4-DCP concentration was measured by a Waters e2569 HPLC, equipped with a Waters reverse-phase C18 column (4.6 $\mathrm{mm} \times 150 \mathrm{~mm}, 3.5 \mu \mathrm{m}$, XBridge, Ireland) and a Waters 2489 UV-Vis detector. The mobile phase was a mixture of methanol and ultrapure water $(80 / 20, \mathrm{v} / \mathrm{v})$ at a flow rate of $0.5 \mathrm{~mL} \mathrm{~min}^{-1}$. The maximum absorption wavelength was detected at $285 \mathrm{~nm}$.

The effects of several active radicals on reaction system were investigated to understand the photocatalytic mechanism. $1.0 \mathrm{mM}$ isopropanol (IPA), 1, 4-benzoquinone (BQ), or disodium ethylenediaminetetraacetate (EDTA-2Na) was added for capturing hydroxyl radicals $(\cdot \mathrm{OH})$, superoxide radicals $\left(\mathrm{O}_{2}^{-}\right)$, or holes $\left(\mathrm{h}^{+}\right)$, respectively $[21,22]$.

The measurement of $\cdot \mathrm{OH}$ amount was accomplished according to the literature [22]. A Shimadzu RF-5301PC fluorescence spectrophotometer was used to measure the signal of 2-hydroxy terephthalic acid (TAOH) and the excitation light employed during recording fluorescence spectra was $320 \mathrm{~nm}$. ESR Signals of radicals spin-trapped by 5,5 -dimethyl-1-pyrroline- $N$-oxide (DMPO) were measured on a FA200 spectrometer. The settings for spectrometer were as follows: $\lambda=425 \mathrm{~nm}$, center field, $323.357 \mathrm{mT}$; microwave frequency, $9.05 \mathrm{GHz}$; power, $0.998 \mathrm{~mW}$.

\section{Results and discussion}

\subsection{Crystalline}

The phase, crystallinity, and purity of $\mathrm{Bi}_{12} \mathrm{O}_{17} \mathrm{Cl}_{2}$ samples synthesized with different PVP amounts were measured by XRD patterns, as shown in Fig. 1. Diffraction peaks in all samples can be unambiguously indexed to the typical tetragonal phase of $\mathrm{Bi}_{12} \mathrm{O}_{17} \mathrm{Cl}_{2}$ (JCPDS No. 37-0702, lattice constants $a=b=0.544 \mathrm{~nm}$, $c=3.52 \mathrm{~nm}) \cdot[13,14,16]$ No other peaks originating from PVP or impurities are observable, implying the high purity and single phase of well-crystallized $\mathrm{Bi}_{12} \mathrm{O}_{17} \mathrm{Cl}_{2}$ samples. The intensity ratio of both diffraction peaks from (117) and (0012) planes that center at $29.2^{\circ}$ and $30.5^{\circ}$ varies from BP0 to BP3, possibly owning to the

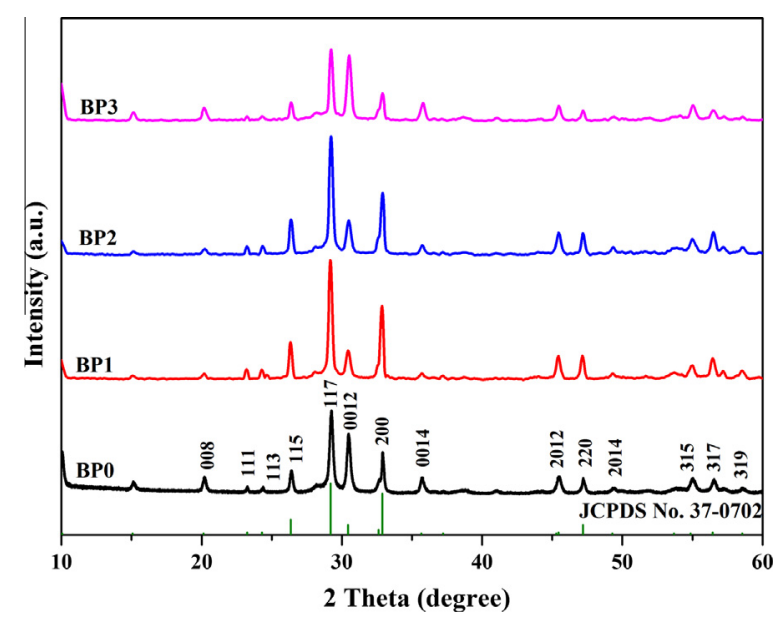

Fig. 1. XRD patterns of the as-synthesized $\mathrm{Bi}_{12} \mathrm{O}_{17} \mathrm{Cl}_{2}$ samples. different crystal panel direction upon different synthetic conditions. As depicted in Fig. 1, sample BP1 and BP2 have relatively wide diffraction peaks in comparison with sample BP0 when a proper amount of PVP surfactant was introduced, revealing the well-crystallized products in small crystallite sizes that are also shown in Table 1. According to the Debye-Scherrer formula, the average crystallite size of sample BP2 $(34.9 \mathrm{~nm})$ is smallest among those of all $\mathrm{Bi}_{12} \mathrm{O}_{17} \mathrm{Cl}_{2}$ samples. These results reveal that the involvement of PVP has effects on the control of crystallization and crystallite size of as-prepared $\mathrm{Bi}_{12} \mathrm{O}_{17} \mathrm{Cl}_{2}$ samples [23].

\subsection{Morphology and microstructures}

Typical SEM images of $\mathrm{Bi}_{12} \mathrm{O}_{17} \mathrm{Cl}_{2}$ series synthesized with variable PVP concentrations are shown in Fig. 2. It is clear that all lamellar samples are loosely assembled by nanosheets with the thickness about several tens nanometers. Without the addition of PVP, nanosheets in sample BP0 microstructures tend to aggregate to large clusters by means of plane to plane assembly, as displayed in Fig. 2A. When $0.1 \mathrm{~g}$ of PVP surfactant was charged, sizes of clusters reduce in a uniform manner and some nanosheets interweave along edges with each other, instead of plane to plane assembly. Further increase PVP to an appropriate amount $(0.2 \mathrm{~g})$ benefits the generation of uniform 3D hierarchical flower-like microspheres with an average diameter of $0.5 \mu \mathrm{m}$, as circled by yellow dotted lines in inset of Fig. 2C. In addition, there are plenty of pores on the surface of microspheres, possibly implying a large specific surface area. 3D hierarchical structures are maintained while flowerlike microspheres are destructed when PVP addition is beyond $0.2 \mathrm{~g}$, as seen in Fig. 2D. To clarify microstructures, sample BP0 and BP2 were subjected to a sonication treatment in ethanol prior to recording SEM and TEM images, as shown in Fig. 3. SEM images of sample BP0 and BP2 (Fig. $3 \mathrm{~A}$ and $\mathrm{B}$ ) demonstrate that asobtained $\mathrm{Bi}_{12} \mathrm{O}_{17} \mathrm{Cl}_{2}$ samples consist of numerous irregular twodimensional nanosheets. Similar to the 2D ordered lamellar architectures of $\mathrm{BiOCl}, \mathrm{Bi}_{12} \mathrm{O}_{17} \mathrm{Cl}_{2}$ nanosheets also exhibit preferential growth in the $2 \mathrm{D}$ plane perpendicular to the $c$-axis $[13,24]$. Further observation discloses that the size of BP2 nanosheets is much smaller than that of BP0 while the thickness of nanosheets in sample BP2 is around $23 \mathrm{~nm}$ that is almost identical to that in sample BP0. The enlarged SEM and TEM images (Fig. 3C and D) of sample BP2 show these nanosheets with a diameter below $1.5 \mu \mathrm{m}$. The HRTEM image of a typical single $\mathrm{Bi}_{12} \mathrm{O}_{17} \mathrm{Cl}_{2}$ nanosheet in Fig. 3E clarifies the highly crystalline nature and clear lattice fringes. The mutually perpendicular lattice fringes of $0.272 \mathrm{~nm}$ correspond to (200) and (020) crystallographic planes of $\mathrm{Bi}_{12} \mathrm{O}_{17} \mathrm{Cl}_{2}$. The periodical diffraction spot arrays in SAED patterns (inset of Fig. 3E) can be assigned to the (200) and (020) planes of $\mathrm{Bi}_{12} \mathrm{O}_{17} \mathrm{Cl}_{2}$, further confirming the formation of crystalline $\mathrm{Bi}_{12} \mathrm{O}_{17} \mathrm{Cl}_{2}$ with a pure tetragonal phase. The EDX spectrum in Fig. 3F indicates that the as-prepared sample contains elements $\mathrm{Bi}, \mathrm{O}$, and $\mathrm{Cl}$. Relative quantitative analysis shows that the atomic ratio of $\mathrm{Bi}$ to $\mathrm{Cl}$ is quite close to 6 , in accordance with the stoichiometric $\mathrm{Bi}_{12} \mathrm{O}_{17} \mathrm{Cl}_{2}$. However, the atomic proportion of $\mathrm{O}$ element is slightly higher than the theoretical value, maybe arising from the influence of the $\mathrm{OH}^{-}$and $\mathrm{H}_{2} \mathrm{O}$ adsorbed on surface of samples [25].

Table 1

Composition, specific surface area, crystallite size, band gap, and apparent rate constant of as-synthesized $\mathrm{Bi}_{12} \mathrm{O}_{17} \mathrm{Cl}_{2}$ samples.

\begin{tabular}{llllll}
\hline Samples & $\begin{array}{l}\text { PVP } \\
(\mathrm{g})\end{array}$ & $\begin{array}{l}S_{\mathrm{BET}} \\
\left(\mathrm{m}^{2} \mathrm{~g}^{-1}\right)\end{array}$ & $\begin{array}{l}\text { Crystallite size } \\
(\mathrm{nm})\end{array}$ & $\begin{array}{l}E_{\mathrm{g}} \\
(\mathrm{eV})\end{array}$ & $\begin{array}{l}k \\
\left(\mathrm{~min}^{-1}\right)\end{array}$ \\
\hline BP0 & 0 & 4.4 & 39.7 & 2.57 & 0.0056 \\
BP1 & 0.1 & 3.5 & 35.3 & 2.56 & 0.0192 \\
BP2 & 0.2 & 10.6 & 34.9 & 2.54 & 0.0319 \\
BP3 & 0.3 & 7.7 & 37.5 & 2.53 & 0.0026 \\
\hline
\end{tabular}




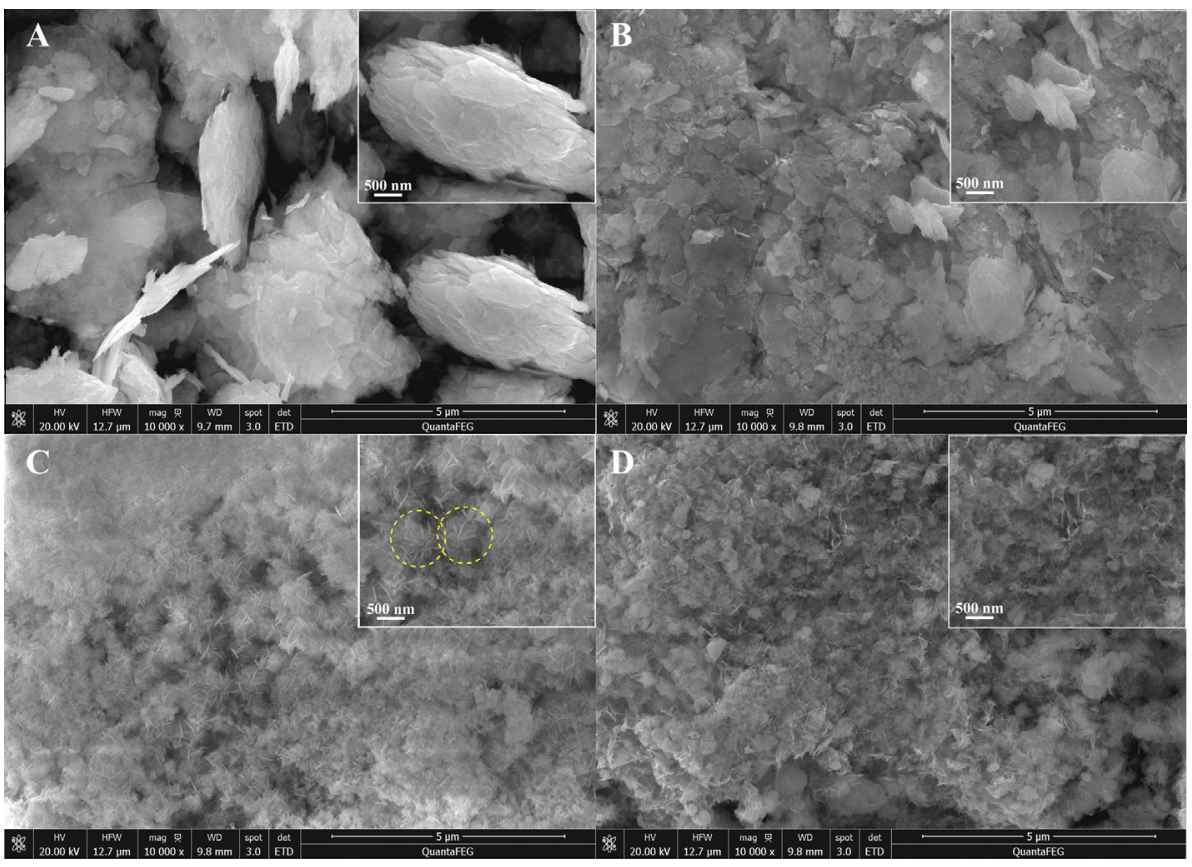

Fig. 2. SEM and enlarged SEM image (inset) of BP0 (A), BP1 (B), BP2 (C), and BP3 (D).

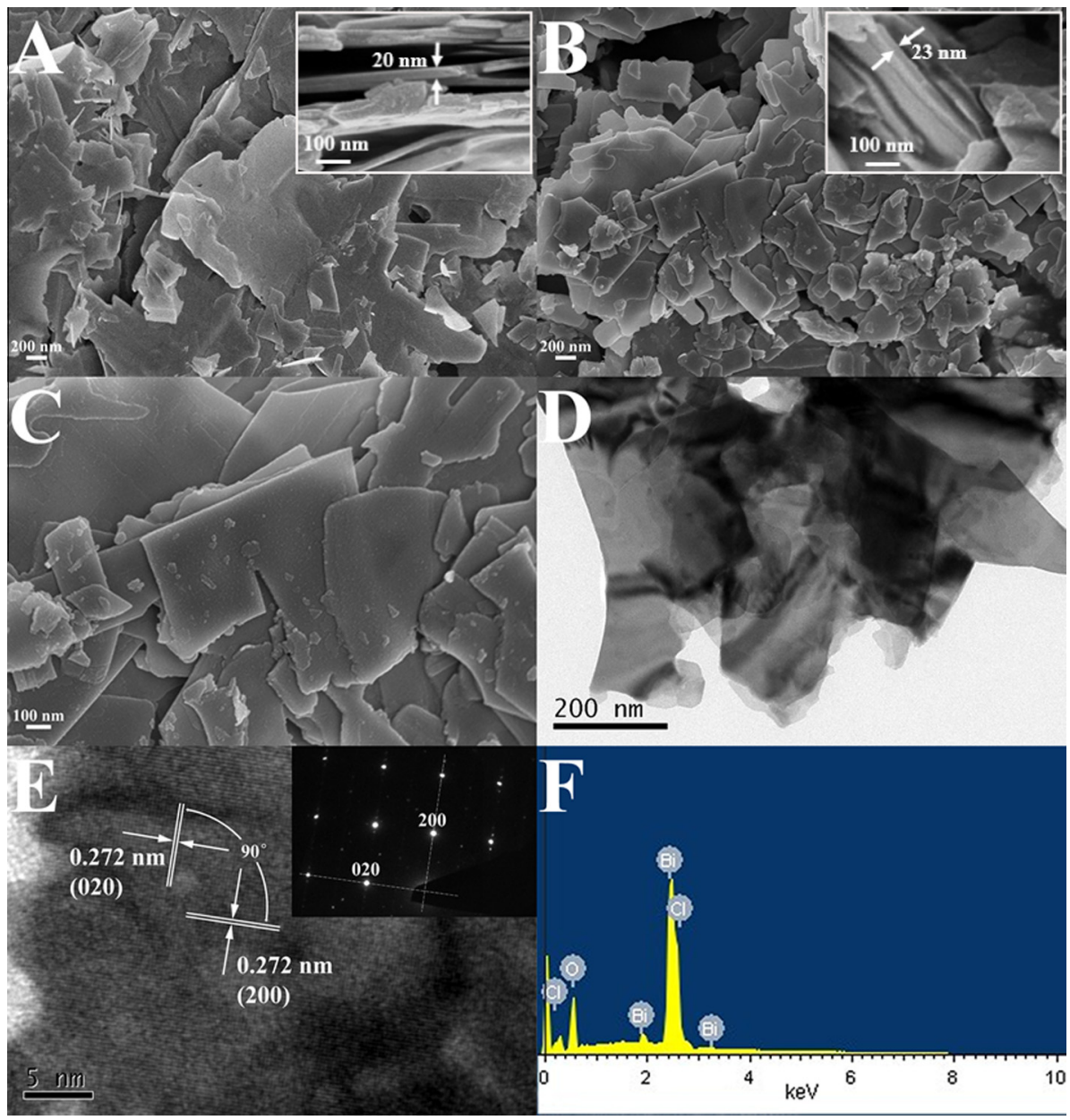

Fig. 3. SEM images of BPO (A) and BP2 (B), enlarged SEM image (C), TEM image (D), HRTEM image (E), and SAED pattern (F). 
A possible process for the formation of sample $\mathrm{Bi}_{12} \mathrm{O}_{17} \mathrm{Cl}_{2}$ is described as from Eqs. (1)-(6) [26].

$$
\begin{aligned}
& \mathrm{Bi}^{3+}+\mathrm{Cl}^{-}+2 \mathrm{OH}^{-} \rightarrow \mathrm{BiOCl}_{(\mathrm{s})}+\mathrm{H}_{2} \mathrm{O} \\
& 4 \mathrm{BiOCl}_{(\mathrm{s})}+2 \mathrm{OH}^{-} \rightarrow \mathrm{Bi}_{4} \mathrm{O}_{5} \mathrm{Cl}_{2(\mathrm{~s})}+2 \mathrm{Cl}^{-}+\mathrm{H}_{2} \mathrm{O} \\
& 6 \mathrm{Bi}_{4} \mathrm{O}_{5} \mathrm{Cl}_{2(\mathrm{~s})}+2 \mathrm{OH}^{-} \rightarrow \mathrm{Bi}_{24} \mathrm{O}_{31} \mathrm{Cl}_{10(\mathrm{~s})}+2 \mathrm{Cl}^{-}+\mathrm{H}_{2} \mathrm{O} \\
& \mathrm{Bi}_{24} \mathrm{O}_{31} \mathrm{Cl}_{10(\mathrm{~s})}+2 \mathrm{OH}^{-} \rightarrow 8 \mathrm{Bi}_{3} \mathrm{O}_{4} \mathrm{Cl}_{(\mathrm{s})}+2 \mathrm{Cl}^{-}+\mathrm{H}_{2} \mathrm{O} \\
& 5 \mathrm{Bi}_{3} \mathrm{O}_{4} \mathrm{Cl}_{(\mathrm{s})}+2 \mathrm{OH}^{-} \rightarrow 3 \mathrm{Bi}_{5} \mathrm{O}_{7} \mathrm{Cl}_{(\mathrm{s})}+2 \mathrm{Cl}^{-}+\mathrm{H}_{2} \mathrm{O} \\
& 12 \mathrm{Bi}_{5} \mathrm{O}_{7} \mathrm{Cl}_{(\mathrm{s})}+2 \mathrm{OH}^{-} \rightarrow 5 \mathrm{Bi}_{12} \mathrm{O}_{17} \mathrm{Cl}_{2(\mathrm{~s})}+2 \mathrm{Cl}^{-}+\mathrm{H}_{2} \mathrm{O}
\end{aligned}
$$

These equations display that $\mathrm{Bi}\left(\mathrm{NO}_{3}\right)_{3} \cdot 5 \mathrm{H}_{2} \mathrm{O}$ is easily decomposed to $\mathrm{Bi}^{3+}$ ions that subsequently react with $\mathrm{Cl}^{-}$and $\mathrm{OH}^{-}$to produce colloidal $\mathrm{BiOCl}$. Those $\mathrm{Cl}$ species in crystal structure are gradually substituted by $\mathrm{OH}^{-}$ions in basic conditions and high temperature, resulting into the reduced content of $\mathrm{Cl}$ atoms in products, characteristic of oxygen-rich bismuth oxychloride derivatives. PVP was usually used as a surfactant to control reaction process, such as reducing surface tension, stabilizing nanoparticles, and regulating nucleation and crystal growth in syntheses, to generate nanomaterials with various morphologies [27]. First, PVP tends to act as a potential crystal face inhibitor in reaction, which promotes the generation of oriented nucleation, further causing the fabrication of preferential growth in the 2D plane perpendicular to the $c$-axis $[13,24]$. The anisotropic growth of $\mathrm{Bi}_{12} \mathrm{O}_{17} \mathrm{Cl}_{2}$ nanoparticles was somewhat restrained since PVP molecules adsorbed on the surface of nanoparticles with the steric hindrance from carbon chains as hydrophobic groups, 2D nanosheets are hereby produced in relatively small sizes. Second, selective adsorption of PVP surfactants on various crystal planes and subsequent competition at interfaces pioneered the rotation of adjacent nanoparticles so that 3D hierarchical architectures are constructed via interweaving 2D nanosheets along edges [28]. As a result, the presence of PVP benefits the assembly and interlacement of 2D nanosheets to construct 3D hierarchical microspheres with numerous pores on surface. An excess amount of PVP may possibly inhibit the connection and assembly of $\mathrm{Bi}_{12} \mathrm{O}_{17} \mathrm{Cl}_{2}$ nanosheets, and thus prevent the formation of ordered $3 \mathrm{D}$ geometry.

\section{3. $X P S$}

The chemical composition and surface valence states of sample BP2 were further investigated by XPS analysis, shown in Fig. 4. The peak positions in all XPS spectra were calibrated with $C 1 \mathrm{~s}$ at $284.6 \mathrm{eV}$. The full scan XPS spectrum in Fig. 4A indicates the presence of elements $\mathrm{Bi}, \mathrm{O}$, and $\mathrm{Cl}$ in product. The high-resolution XPS spectra of $\mathrm{Bi} 4 \mathrm{f}, \mathrm{O} 1 \mathrm{~s}$, and $\mathrm{Cl} 2 \mathrm{p}$ were shown in Fig. 4B-D. Two strong peaks at $158.54 \mathrm{eV}$ and $163.83 \mathrm{eV}$ in Fig. 4B are attributed to $\mathrm{Bi} 4 \mathrm{f}_{7 / 2}$ and $\mathrm{Bi} 4 \mathrm{f}_{5 / 2}$ that are characteristics of $\mathrm{Bi}^{3+}$ species in matrix, respectively. The $O 1 \mathrm{~s}$ spectrum in Fig. $4 \mathrm{C}$ could be fitted well with two peaks at 530.19 and $531.60 \mathrm{eV}$. The former peak is assigned to the $\mathrm{Bi}-\mathrm{O}$ bond and another peak may be due to the $\mathrm{OH}^{-}$and $\mathrm{H}_{2} \mathrm{O}$ absorbed on surface, which is in accordance with the result of relatively high atomic proportion of $\mathrm{O}$ than the theoretical value in morphology and microstructure section. Both peaks located at $196.9 \mathrm{eV}$ and $198.5 \mathrm{eV}$ represent to $\mathrm{Cl} 2 \mathrm{p}_{3 / 2}$ and $\mathrm{Cl} 2 \mathrm{p}_{1 / 2}$,
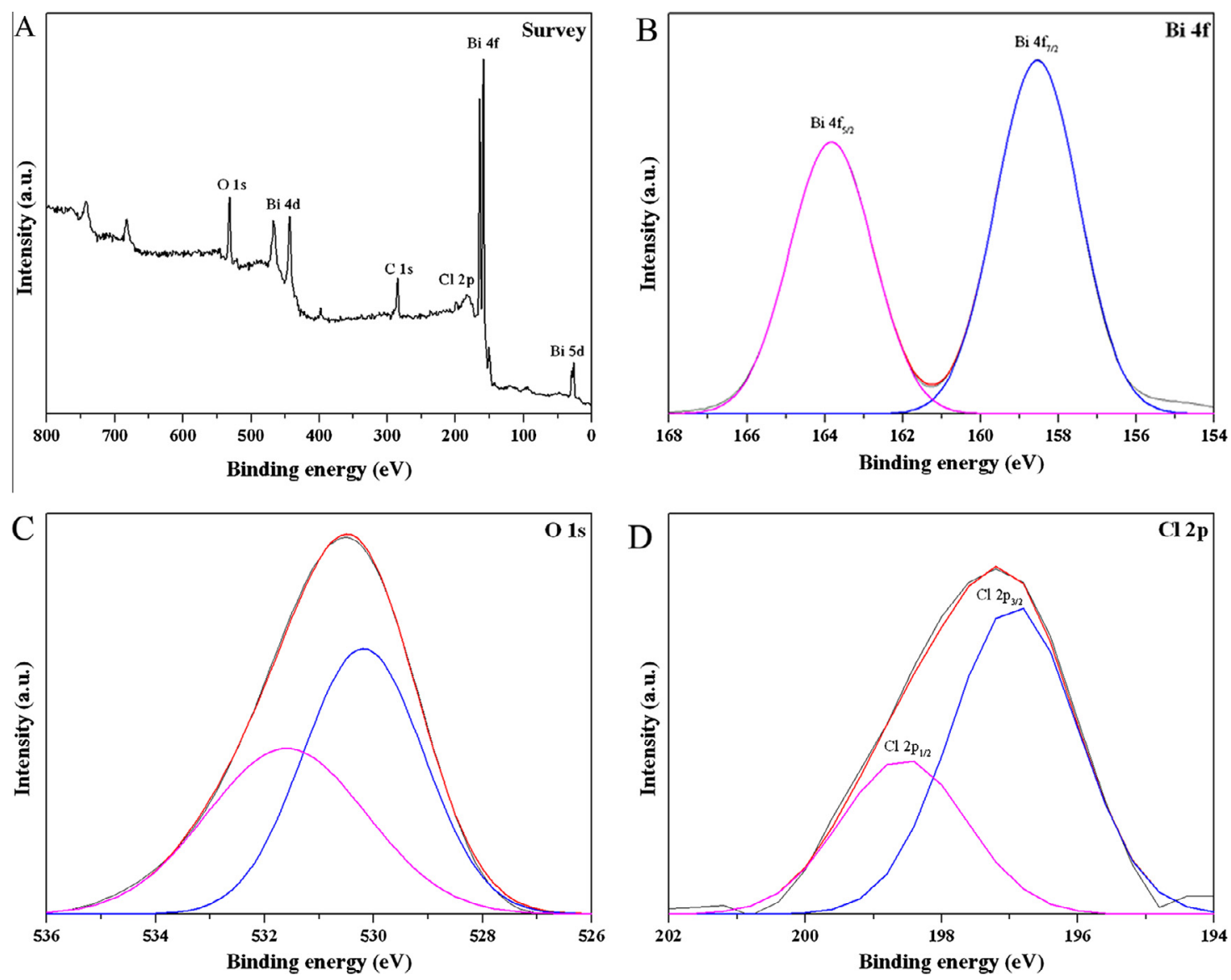

Fig. 4. XPS spectra of sample BP2: survey spectrum (A), high-resolution XPS spectrum of Bi $4 f(B), O$ s $(C)$, and Cl 2p (D). 
respectively, and are in good agreement with the valence state of $1 \mathrm{in} \mathrm{Cl}$ species, as seen in Fig. 4D. The measured binding energies of $\mathrm{Bi}, \mathrm{O}$ and $\mathrm{Cl}$ are quite close to previous reported values of $\mathrm{BiOCl}$ $[13,14,29]$.

\subsection{UV-vis DRS}

Fig. 5A shows the UV-Vis diffuse reflectance spectra of the assynthesized $\mathrm{Bi}_{12} \mathrm{O}_{17} \mathrm{Cl}_{2}$ samples. According to the spectra, the $\mathrm{Bi}_{12} \mathrm{O}_{17} \mathrm{Cl}_{2}$ sample represents the photoresponsive property ranging from UV to visible light region until near $490 \mathrm{~nm}$, which is consistent with the yellow color of samples. The band gap energy $\left(E_{\mathrm{g}}\right)$ of as-synthesized $\mathrm{Bi}_{12} \mathrm{O}_{17} \mathrm{Cl}_{2}$ samples could be estimated by an empirical equation $\alpha h v=A\left(h v-E_{\mathrm{g}}\right)^{n / 2}$, where $\alpha, h v$, and $A$ are absorption coefficient, photon energy, and a constant, respectively. Among them, $n$ depends on characteristics of the transition in a semiconductor ( $n=1$ for direct transition and $n=4$ for indirect transition) and was estimated at 1 by plotting $\ln (\alpha h v)$ versus $\ln$ $\left(h v-E_{\mathrm{g}}\right)$ to form a straight line near the band edge on the basis of an approximate value of $E_{\mathrm{g}}$ in inset of Fig. 5A, indicating the direct transition of the $\mathrm{Bi}_{12} \mathrm{O}_{17} \mathrm{Cl}_{2}$ sample [14]. Band gap energies are determined as $2.57 \mathrm{eV}, 2.56 \mathrm{eV}, 2.54 \mathrm{eV}$ and $2.53 \mathrm{eV}$ for sample $\mathrm{BP0}, \mathrm{BP} 1, \mathrm{BP} 2$, and BP3, respectively, by means of the plot of $(\alpha h v)^{2}$ versus $h v$, as depicted in inset of Fig. 5B and listed in Table 1 . These values are slightly larger than those literature values $[14,24]$. It is general accepted that $E_{\mathrm{g}}$ value is relevant to a degree of the thickness of nanosheets [30] and in our cases, the thickness of nanosheets are almost identical no matter whether PVP is added or not. The slight shrinkage of band gap energy of three BPx samples may possibly relate to the variable morphology, crystal size, and specific structure, indicating that PVP can be utilized as a structure directing agent for fabricating nanostructures with favorable structural features [28]. As expected, semiconductors with suitable band gaps benefit the absorption and utilization of visible light, and thus further enhancement of photocatalytic efficiency. By means of the valence-band X-ray photoelectron spectroscopy (VB XPS) spectrum of sample BP2 in Fig. $5 \mathrm{C}$, the position of valence band (VB) edge of $\mathrm{Bi}_{12} \mathrm{O}_{17} \mathrm{Cl}_{2}$ was measured at $2.14 \mathrm{eV}$, which is consistent with the previous report [24]. Correspondingly, the conduction band (CB) edge of $\mathrm{Bi}_{12} \mathrm{O}_{17} \mathrm{Cl}_{2}$ was calculated to be $-0.40 \mathrm{eV}$ using the equation of $E_{\mathrm{CB}}=E_{\mathrm{VB}}-E_{\mathrm{g}}$.

\section{5. $P L$}

PL emission spectra were measured to study the separation efficiency of charge carriers to realize the fate of photogenerated electrons and holes in semiconductors [31], as shown in Fig. 5D. One peak at $\sim 524 \mathrm{~nm}$ in BP0 is attributed to the charge-transfer transitions between the $\mathrm{VB}$ and $\mathrm{CB}$ of $\mathrm{Bi}_{12} \mathrm{O}_{17} \mathrm{Cl}_{2}$. Another strong peak at $\sim 488 \mathrm{~nm}$ is related to the surface-defect emission, which is determined by the surface states such as oxygen vacancies originated from the fast growth rate [32]. However, other BPx samples show merely one broad peak centered at nearly $520 \mathrm{~nm}$ with relatively low PL intensity in comparison with sample BP0. Especially, the
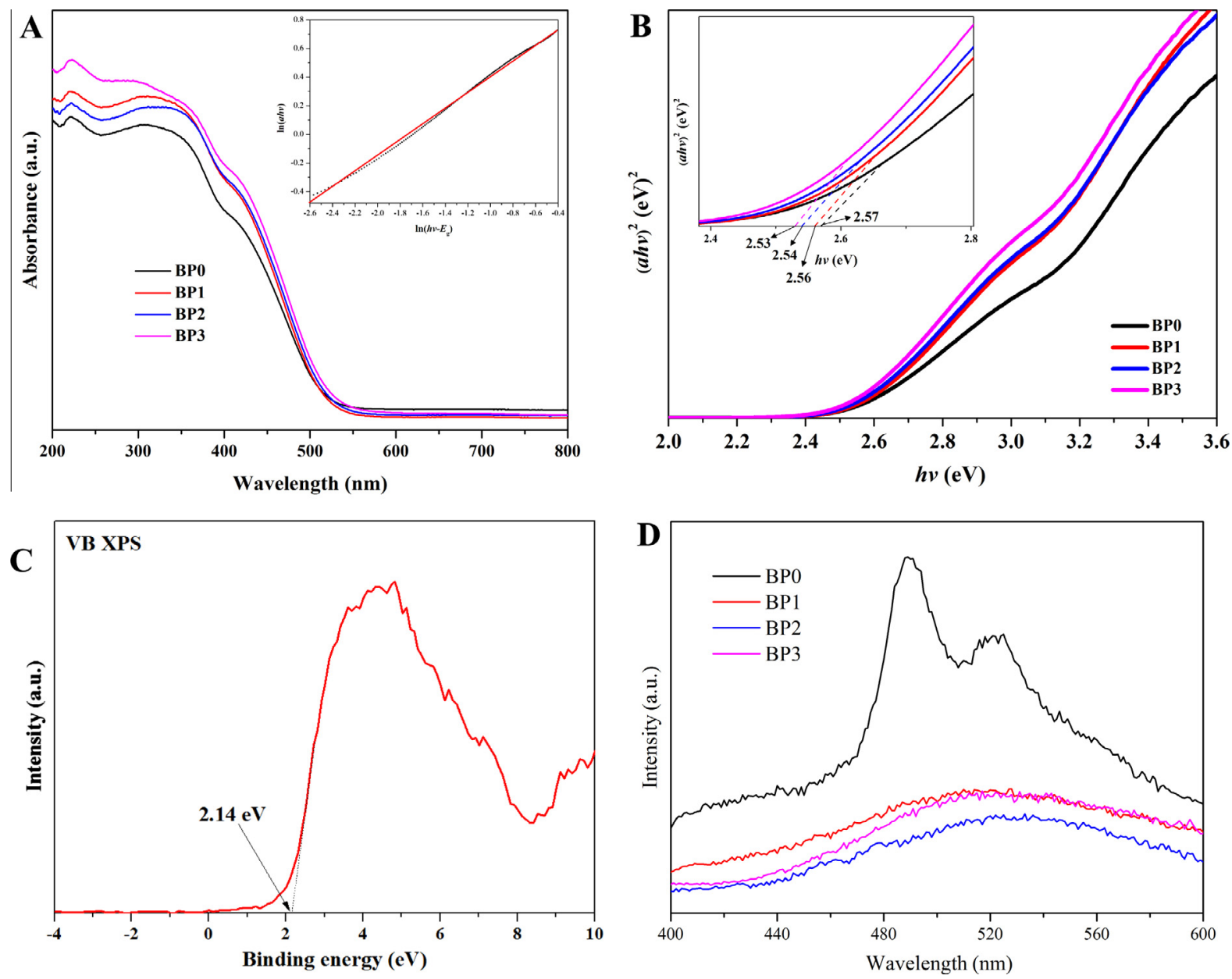

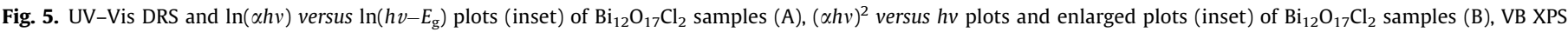
spectra of sample BP2 (C), and the photoluminescence spectra of $\mathrm{Bi}_{12} \mathrm{O}_{17} \mathrm{Cl}_{2}$ series at room temperature $\left(\lambda_{\mathrm{Ex}}=324 \mathrm{~nm}\right)(\mathrm{D})$. 
sample BP2 exhibits the PL emission peak with the lowest intensity among all samples, ensuring the highest separation efficiency of charge carriers and thus longest lifetime of photogenerated electron-hole pairs. This may be attributed to the good crystallinity and relatively small crystallite size of sample BP2. It is well known that the effective separation and transport of charge carriers can induce the improvement of catalytic performance [33]. Hence, based on above results and analysis, it is reasonable to deduce that sample BP2 may exhibit superior photocatalytic activity to other samples.

\subsection{Photocatalytic performance}

The phtocatalytic activities of as-prepared $\mathrm{Bi}_{12} \mathrm{O}_{17} \mathrm{Cl}_{2}$ samples were evaluated through catalytic degradation of dye $\mathrm{RhB}$ and 2,4-DCP under visible-light irradiation. Fig. 6A exhibits the temporal evolution of the adsorption spectra of RhB solution over sample BP2. It is observable that the intensity of the absorption peak decreases gradually with increasing irradiation time, accompanying with a blue shift of the main adsorption peak from $554 \mathrm{~nm}$ to $501 \mathrm{~nm}$, which is ascribed to a step-by-step deethylation of RhB molecules $[34,35]$. During the progress of photocatalytic reaction, the color of solution gradually changed from initial fuchsia red to light green-yellow after irradiation for $150 \mathrm{~min}$. Furthermore, the stepwise decrease of the peaks centered at 250 and $300 \mathrm{~nm}$ suggests the destruction of conjugated structure of $\mathrm{RhB}[35,36]$. In order to simplify the analysis, the characteristic adsorption peak at $554 \mathrm{~nm}$ was selected to record the photocatalytic outcome, as shown in Fig. 6B. It is found that the direct photolysis of dye RhB can almost be negligible and $\mathrm{N}$-doped $\mathrm{TiO}_{2}$ displays quite low photocatalytic performance in this investigation. However, the residual concentration of $\mathrm{RhB}$ obviously decreases in the presence of the as-synthesized $\mathrm{Bi}_{12} \mathrm{O}_{17} \mathrm{Cl}_{2}$ samples, implying the significant photocatalytic degradation efficiency under identical conditions. The photocatalytic ability of all tested BP series gradually enhances as increasing the PVP addition during the synthetic procedure. Among these photocatalysts, sample BP2 exhibits the best catalytic capability and can completely destruct RhB after $150 \mathrm{~min}$. Fig. 6C shows the degradation efficiency (DE) after $90 \mathrm{~min}$ irradiation and corresponding apparent rate constants $(k)$ of measured samples, calculated from a pseudo first-order reaction kinetic model. It is pronounced that sample BP2 are able to effectively catalyze the decomposition of $\mathrm{RhB}$, showing the highest $k$ value of $0.0319 \mathrm{~min}^{-1}$ that is nearly 5.7 and 45 times that of unmodified $\mathrm{BPO}$ and $\mathrm{N}-\mathrm{TiO}_{2}$.

Since dye RhB is sensitive to visible light irradiation, the degradation of RhB can be mainly attributed to a dye-sensitized path, revealing the band gap excitation of a semiconductor is not necessary. Hence, 2,4-DCP, a colorless organic compound, was specially chosen to evaluate the visible-light photocatalytic performance in Fig. 6D. As can be seen, after 210 min visible-light illumination, the photodecomposition efficiencies of 2,4-DCP are $24 \%, 32 \%$ and $42 \%$
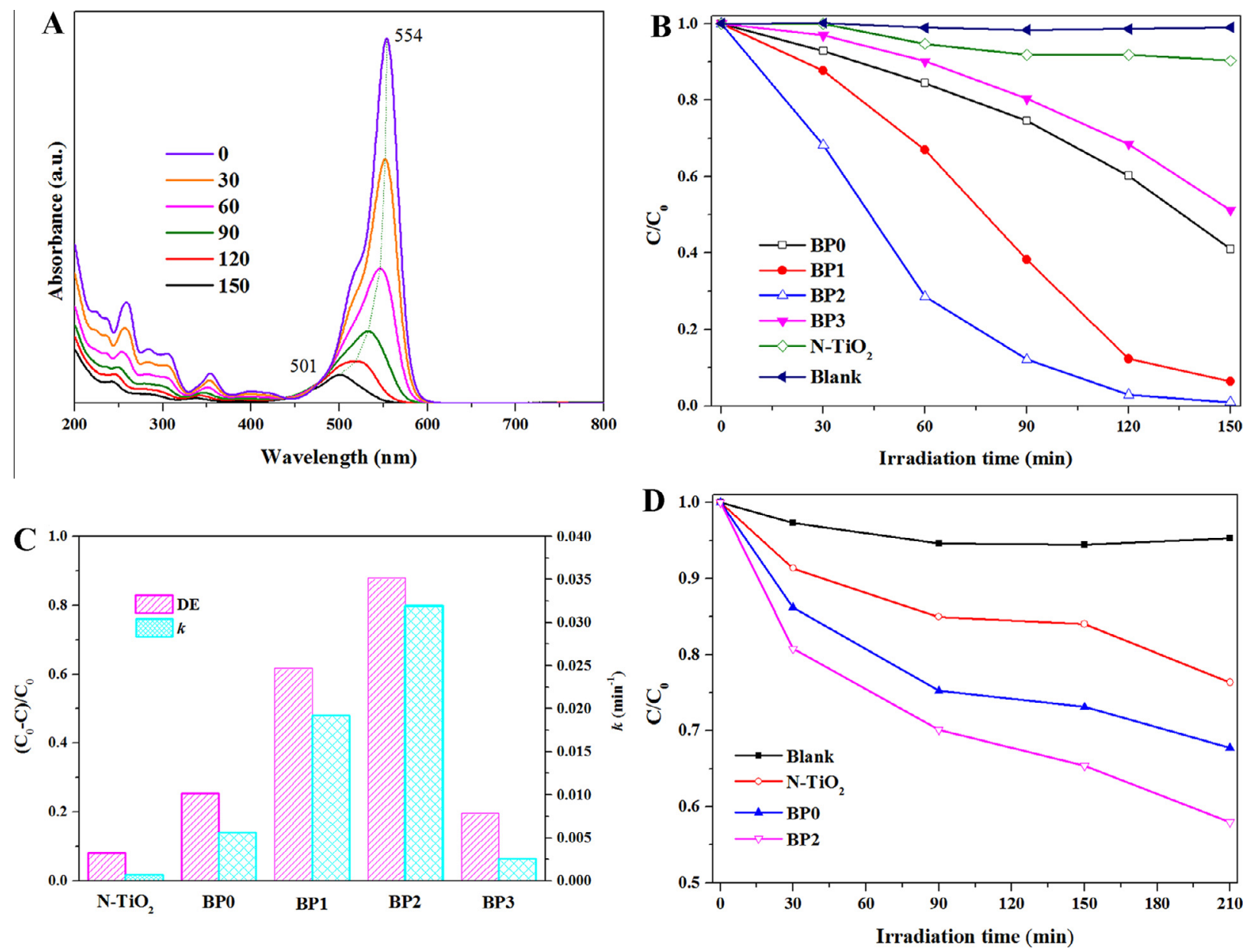

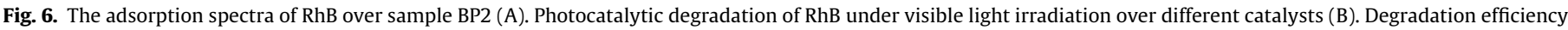
$(\mathrm{DE})$ of $\mathrm{RhB}$ at $t=90 \mathrm{~min}$ and apparent reaction rate $(k)(\mathrm{C})$. Photocatalytic degradation of 2,4-DCP over $\mathrm{Bi}_{12} \mathrm{O}_{17} \mathrm{Cl}_{2}$ samples (D). 

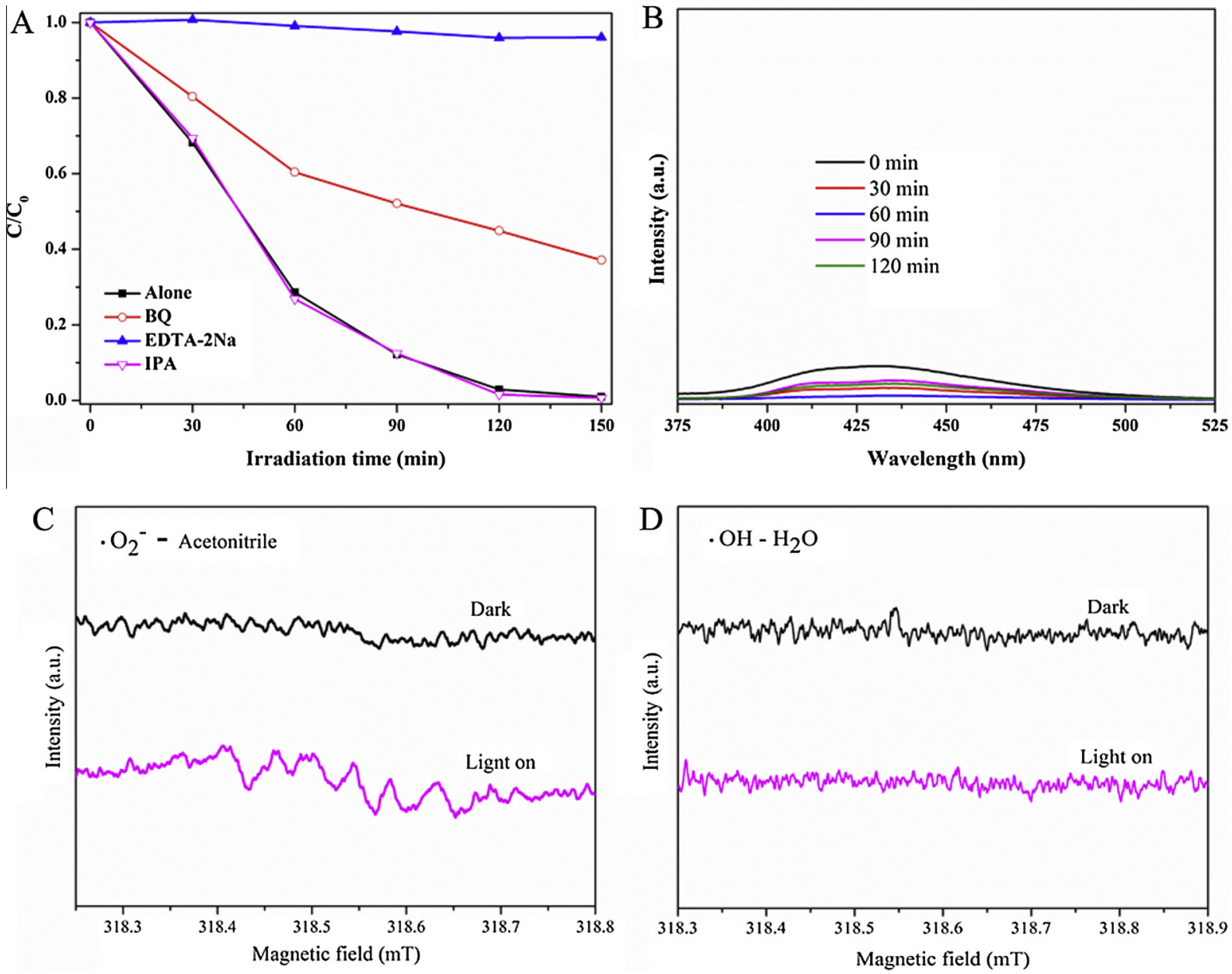

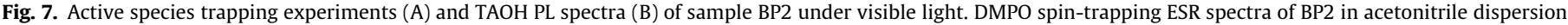
for DMPO- $\mathrm{O}_{2}^{-}(\mathrm{C})$ and DMPO spin-trapping ESR spectra of BP2 in water dispersion for DMPO-'OH (D).

for $\mathrm{N}-\mathrm{TiO}_{2}, \mathrm{BPO}$ and $\mathrm{BP} 2$, respectively. It is obvious that $\mathrm{BP} 2$ has the ability to exert relatively high catalytic performance toward degradation of organic compounds under visible light.

Based upon the experimental, the improvement of photocatalytic performance of modified $\mathrm{Bi}_{12} \mathrm{O}_{17} \mathrm{Cl}_{2}$ samples ascribes to a synergetic effect of several factors. First, it is usual that a semiconductor with large specific surface area benefits the absorption of visible light approaching to the surface, more electrons and holes are thus generated to accelerate the photocatalytic reaction. In addition, a large specific surface area tends to supply abundant active sites exposed to the solution, facilitating the contact and further reaction between catalyst and organic molecules, thus enhancing the catalytic efficiency $[37,38]$. It is found in Table 1 that the specific surface area is enlarged with the increase of PVP addition and with a proper addition amount of $0.2 \mathrm{~g}$, the corresponding sample BP2 possesses the largest value $\left(10.6 \mathrm{~m}^{2} \mathrm{~g}^{-1}\right)$ among all BP samples. Second, the smaller average crystal size and better crystallinity of modified BP samples allow more efficient transfer and separation of photogenerated electron-hole pairs, depressing the recombination rate of charge carriers [39]. it was also proven by the relatively low intensity of PL peak in BP2 in comparison with other BPx samples [40]. Third, the 3D hierarchical structure has numerous pores on surface, which favors the mass transfer of reactants into the interior and product molecules out, thus promoting the catalytic degradation process [28]. Besides, the enhancement of visible-light harvesting is available through the multiple reflections of incident radiation, which is favorable to the increase of catalytic efficiency [35]. As stated, the enhancement of catalytic efficiency of modified BP samples mainly attributes to the superior hierarchical flower-like structures with sufficient pores on surface, large specific surface area, small average crystal size, good crystallinity, and suitable band structure.

\subsection{Photocatalytic mechanism}

The detection of main active radical species in a photocatalytic system is required to realize the photocatalytic mechanism. As shown in Fig. 7A, in a catalytic process with sample BP2, the involvement of IPA induces almost no change in the degradation of $\mathrm{RhB}$, indicating that $\cdot \mathrm{OH}$ radicals are not the main active species, which is also confirmed by the nearly unchangeable photoluminescence spectra of TAOH in Fig. 7B. In contrast, the photodecomposition of RhB greatly reduces from $100 \%$ to $63 \%$ by adding BQ. In addition, the addition of EDTA-2Na is able to completely inhibit the photocatalytic degradation of RhB. These results demonstrate that both $\mathrm{O}_{2}^{-}$and $\mathrm{h}^{+}$are dominant oxidative species during the destruction of $\mathrm{RhB}$ over $\mathrm{Bi}_{12} \mathrm{O}_{17} \mathrm{Cl}_{2}$ samples [17]. The formation of radicals ${ }^{\circ} \mathrm{O}_{2}^{-}$was also certified by ESR with DMPO spin-trap analysis. Six characteristic peaks of DMPO- $\mathrm{O}_{2}^{-}$adduct over sample BP2 in acetonitrile confirm the generation of $\mathrm{O}_{2}^{-}$via the combination of electrons and adsorbed $\mathrm{O}_{2}$. No signals of DMPO-OH adduct detected indicates that $\mathrm{OH}$ species are impossible to form, as depicted in Fig. 7C and D. 


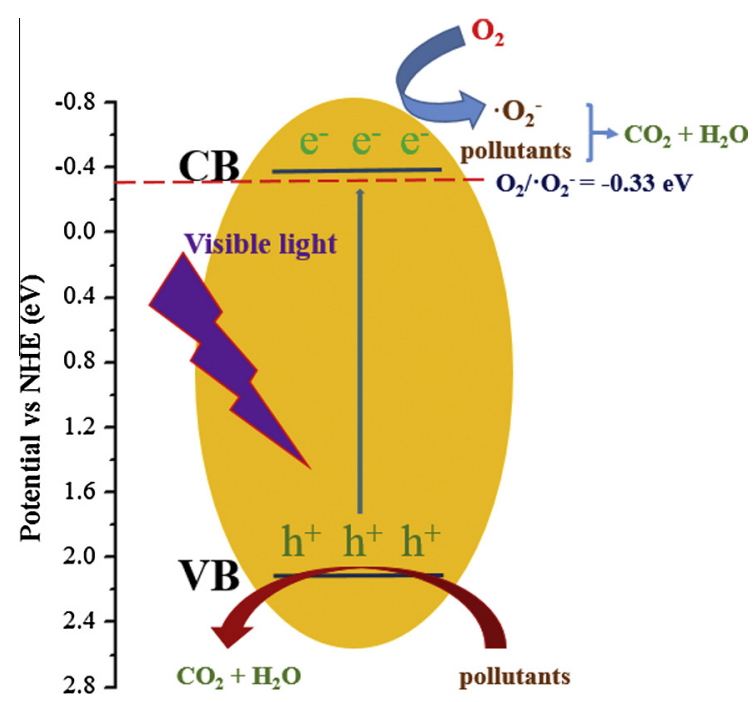

Scheme 1. Proposed mechanism of $\mathrm{Bi}_{12} \mathrm{O}_{17} \mathrm{Cl}_{2}$ sample upon visible light irradiation.
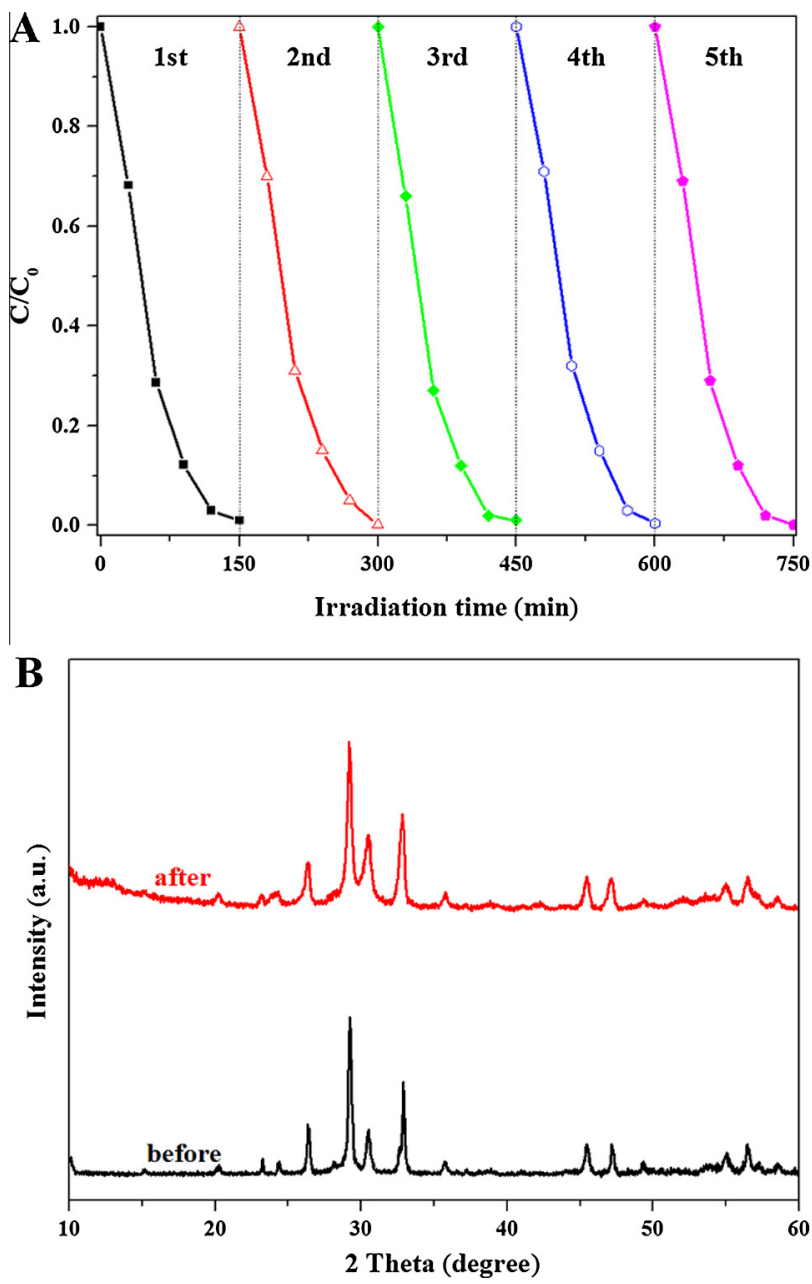

Fig. 8. Recycle experiments of sample BP2 for degradation of RhB under visible light irradiation (A). XRD patterns of the BP2 sample before and after reaction (B).

Based upon experimental results, a possible photocatalytic mechanism was proposed in Scheme 1 . Under visible light irradiation $(\lambda>400 \mathrm{~nm})$, sample $\mathrm{Bi}_{12} \mathrm{O}_{17} \mathrm{Cl}_{2}$ are easily excited to produce photogenerated electron-hole pairs due to the visible light response. Since the $E_{\mathrm{CB}}(-0.40 \mathrm{eV})$ of $\mathrm{Bi}_{12} \mathrm{O}_{17} \mathrm{Cl}_{2}$ is negative than $E$ $\left(\mathrm{O}_{2} / \mathrm{O}_{2}^{-}\right)(-0.33 \mathrm{eV})$, the produced electrons through excitation of semiconductor tend to react with absorbed oxygen molecules on surface to provide active radicals $\mathrm{O}_{2}^{-}$[41]. Since the standard redox potential of $\mathrm{Bi}_{2} \mathrm{O}_{4} / \mathrm{BiO}^{+}\left(\mathrm{Bi}^{\mathrm{V}} / \mathrm{Bi}^{\mathrm{III}}\right)(+1.59 \mathrm{eV})$ is more negative than that of $\cdot \mathrm{OH} / \mathrm{OH}^{-}(+1.99 \mathrm{eV})$, the generated holes cannot directly oxidize $\mathrm{OH}^{-} / \mathrm{H}_{2} \mathrm{O}$ to form $\mathrm{OH}$ radicals on the $\mathrm{VB}$ of $\mathrm{Bi}_{12} \mathrm{O}_{17} \mathrm{Cl}_{2}$ $[42,43]$, which has been proven by TAOH-PL and ESR spectra. Both active species ${ }^{\circ} \mathrm{O}_{2}^{-}$and $\mathrm{h}^{+}$can interact with and subsequently decompose RhB molecules. With the progress of degradation, RhB molecules around active radicals are gradually consumed and more $\mathrm{RhB}$ molecules transfer from solution phase to the surface of $\mathrm{Bi}_{12} \mathrm{O}_{17} \mathrm{Cl}_{2}$ semiconductor for maintaining the adsorption-desorption equilibrium on the basis of Le Chatelier's principle, resulting into the continuous destruction and mineralization of organic contaminates in aqueous solution.

\subsection{Reusability}

The recovery and durability of a given catalyst during a photocatalytic reaction are crucial to industrial applications. As a result, the sample BP2 was typically selected to operate photocatalysis for five runs through simply centrifugation, washed with ethanol and water for several times, and dried in an oven. It is clear that sample BP2 exhibits satisfactory photocatalytic capability even after four recycle runs without significant loss of activity, as shown in Fig. 8A. In addition, the XRD patterns in Fig. 8B show no remarked variation before and after reaction, suggesting the good maintenance of crytallinity and phase structures during photocatalytic process. These results indicate that the modified $\mathrm{Bi}_{12} \mathrm{O}_{17} \mathrm{Cl}_{2}$ samples are effective and robust visible-light-driven photocatalysts and will find real applications in fields of pollutants treatments and water remediation.

\section{Conclusion}

Modified $\mathrm{Bi}_{12} \mathrm{O}_{17} \mathrm{Cl}_{2}$ samples were synthesized via a PVPassisted hydrothermal protocol for the first time, which had been analyzed by a series of characterization techniques. With the presence of appropriate amount of PVP, $\mathrm{Bi}_{12} \mathrm{O}_{17} \mathrm{Cl}_{2}$ nanosheets tended to interweave to produce uniform hierarchical flower-like microspheres BP2 with numerous pores on surface. An excess amount of involved PVP led to generate hierarchical sample BP3 without microspheres. Among all as-synthesized samples, sample BP2 displayed the best catalytic performance toward degradation of $\mathrm{RhB}$ and 2,4-DCP. In particularly, the apparent rate constant of sample BP2 for degradation of RhB was nearly 5.7 and 45 times that of unmodified $\mathrm{BPO}$ and $\mathrm{N}-\mathrm{TiO}_{2}$. The increased photocatalytic behavior could be attributed to synergetic effects of structural and electronic merits. In addition, these BP samples were robust and could be used for five runs without loss of catalytic efficiency. Finally, a possible catalytic mechanism was proposed on base of active radical species trapping experiments.

\section{Acknowledgments}

We are grateful to the National Natural Science Foundation of China (Grant Number 21207089), the project-sponsored by SRF for ROCS, SEM., and the Hujiang Foundation of China (B14003) for financial support.

\section{References}

[1] M.R. Hoffmann, S.T. Martin, W. Choi, D.W. Bahnemann, Environmental applications of semiconductor photocatalysis, Chem. Rev. 95 (1995) 69-96.

[2] R.D.L. Smith, M.S. Prévot, R.D. Fagan, Z. Zhang, P.A. Sedach, M.K.J. Siu, S. Trudel, C.P. Berlinguette, Science 340 (2013) 60-63.

[3] C. Chen, W. Ma, J. Zhao, Chem. Soc. Rev. 39 (2010) 4206-4219.

[4] M. Tahir, N.S. Amin, Appl. Catal. B 142-143 (2013) 512-522. 
[5] X. Chen, S.S. Mao, Chem. Rev. 107 (2007) 2891-2959.

[6] K.L. Zhang, C.M. Liu, F.Q. Huang, C. Zheng, W.D. Wang, Appl. Catal. B 68 (2006) $125-129$.

[7] S. Weng, J. Hu, M. Lu, X. Ye, Z. Pei, M. Huang, L. Xie, S. Lin, P. Liu, Appl. Catal. B 163 (2015) 205-213.

[8] H. Cheng, B. Huang, Y. Dai, Nanoscale 6 (2014) 2009-2026.

[9] J. Li, L. Zhang, Y. Li, Y. Yu, Nanoscale 6 (2014) 167-171.

[10] X. Xiao, R. Hu, C. Liu, C. Xing, X. Zuo, J. Nan, L. Wang, Chem. Eng. J. 225 (2013) $790-797$.

[11] J. Wang, Y. Yu, L. Zhang, Appl. Catal. B 136-137 (2013) 112-121.

[12] C. Chang, L. Zhu, S. Wang, X. Chu, L. Yue, Acs Appl. Mater. Int. 6 (2014) $5083-$ 5093.

[13] X.Y. Chen, H.S. Huh, S.W. Lee, J. Solid State Chem. 180 (2007) 2510-2516.

[14] L.C. Tien, Y.L. Lin, S.Y. Chen, Mater. Lett. 113 (2013) 30-33.

[15] X. Xiao, C. Liu, R. Hu, X. Zuo, J. Nan, L. Li, L. Wang, J. Mater. Chem. 22 (2012) $22840-22843$

[16] X. Xiao, J. Jiang, L. Zhang, Appl. Catal. B 142-143 (2013) 487-493.

[17] G. He, C. Xing, X. Xiao, R. Hu, X. Zuo, J. Nan, Appl. Catal. B 170 (2015) 1-9.

[18] L. Zhou, W. Wang, H. Xu, S. Sun, M. Shang, Chem. -Eur. J. 15 (2009) $1776-1782$.

[19] T. Li, L. Zhao, Y. He, J. Cai, M. Luo, J. Lin, Appl. Catal. B 129 (2013) 255-263.

[20] K. Maeda, K. Teramura, D. Lu, T. Takata, N. Saito, Y. Inoue, K. Domen, Nature 440 (2006) 295

[21] X. Hu, T. Mohamood, W. Ma, C. Chen, J. Zhao, J. Phys. Chem. B 110 (2006) $26012-26018$

[22] F. Chang, Y. Xie, C. Li, J. Chen, J. Luo, X. Hu, J. Shen, Appl. Surf. Sci. 280 (2013) 967-974.

[23] H. Cheng, W. Wang, B. Huang, Z. Wang, J. Zhan, X. Qin, X. Zhang, Y. Dai, J. Mater. Chem. A 1 (2013) 7131-7136.
[24] N. Kijima, K. Matano, M. Saito, T. Oikawa, T. Konishi, H. Yasuda, T. Sato, Y. Yoshimura, Appl. Catal. A 206 (2001) 237-244.

[25] H. Deng, J. Wang, Q. Peng, X. Wang, Y. Li, Chem. -Eur. J. 11 (2005) 6519-6524.

[26] Y.R. Jiang, H.P. Lin, W.H. Chung, Y.M. Dai, W.Y. Lin, C.C. Chen, J. Hazard. Mater, 283 (2015) 787-805.

[27] X. Shi, X. Chen, X. Chen, S. Zhou, S. Lou, Mater. Lett. 68 (2012) 296-299.

[28] S. Peng, L. Li, P. Zhu, Y. Wu, M. Srinivasan, S.G. Mhaisalkar, S. Ramakrishna, Q. Yan, Chem. Asian. J. 8 (2013) 258-268.

[29] J.M. Song, C.J. Mao, H.L. Niu, Y.H. Shen, S.Y. Zhang, CrystEngComm 12 (2010) 3875-3881.

[30] X. Shi, X. Chen, X. Chen, S. Zhou, S. Lou, Y. Wang, L. Yuan, Chem. Eng. J. 222 (2013) 120-127.

[31] X. Jie, W. Wang, S. Meng, E. Gao, Z. Zhang, R. Jia, J. Hazard. Mater. 196 (2011) 426-430.

[32] T.-K. Tseng, J. Choi, D.-W. Jung, M. Davidson, P.H. Holloway, Acs Appl. Mater. Int. 2 (2010) 943-946.

[33] J. Jiang, X. Zhang, P. Sun, L. Zhang, J. Phys. Chem. C 115 (2011) 20555-20564.

[34] Z. Zhang, H. Sun, X. Shao, D. Li, H. Yu, M. Han, Adv. Mater. 17 (2005) 42-47.

[35] Y. Xie, F. Chang, C. Li, J. Chen, J. Luo, L. Li, X. Hu, Clean Soil, Air, Water 42 (2014) 521-527.

[36] J. Fu, Y. Tian, B. Chang, F. Xi, X. Dong, J. Mater. Chem. 22 (2012) 21159-21166.

[37] J. Tang, Z. Zou, J. Ye, Chem. Mater. 16 (2004) 1644-1649.

[38] J. Yu, J. Xiong, B. Cheng, S. Liu, Appl. Catal. B 60 (2005) 211-221.

[39] J. Yu, J. Zhang, M. Jaroniec, Green Chem. 12 (2010) 1611-1614.

[40] J.C. Yu, Yu, Ho, Jiang, Zhang, Chem. Mater. 14 (2002) 3808-3816.

[41] J. Jiang, H. Li, L. Zhang, Chem. -Eur. J. 18 (2012) 6360-6369.

[42] F.T. Li, Q. Wang, X.J. Wang, B. Li, Y.J. Hao, R.H. Liu, D.S. Zhao, Appl. Catal. B 150151 (2014) 574-584.

[43] H. Fu, C. Pan, W. Yao, Y. Zhu, J. Phys. Chem. B 109 (2005) 22432-22439. 